\title{
Increase in HIV sexual risk behaviour in homosexual men in Scotland, 1996-2002: prevention failure?
}

\section{G J Hart, L M Williamson}

See end of article for authors' affiliations

.....................

Correspondence to: Professor Graham Hart MRC Social and Public Health Sciences Unit, University of Glasgow, 4 Lilybank Gardens, Glasgow G12 8RZ, UK; g.harł@msoc.mrc.gla. ac.uk

Accepted for publication 10 January 2005

\begin{abstract}
Objective: To investigate trends in homosexual men's sexual risk behaviour for HIV infection in Scotland. Methods: Cross sectional surveys in 1996, 1999, and 2002 were carried out in "gay" bars in Glasgow and Edinburgh, Scotland. 6508 men-2276 (79\% response rate) in 1996, 2498 (78\%) in 1999, and $1734(62 \%)$ in 2002.

Results: In 1996, 10.7\% of men surveyed and in 1999, 11.2\% reported unprotected anal intercourse (UAI) with casual partners, compared with $18.6 \%$ in 2002 ( $p<0.001)$. There was also a significant increase in men reporting that they "knew" their casual partners' HIV status, despite no increase in HIV testing among men who reported UAI with casual partners. In 2002, increases in UAl with more than one partner, in UAI with casual partners and in reporting seroconcordance remained significant after adjusting for confounding factors including HIV testing status and demographic characteristics.

Conclusions: High risk sexual behaviour among homosexual men in Scotland increased between 1999 and 2002. Men showed increased confidence of shared antibody status, despite no increase in HIV testing, or evidence of discussion of HIV status. Explanations for this must include consideration of a cultural shift in the perception of HIV and "prevention failure" on the part of governments and health agencies.
\end{abstract}

$\mathrm{T}$ he late 1980s and early 1990s saw major reductions in high risk sexual behaviour among homosexual men throughout the developed world. ${ }^{1}$ Recent years however have seen an increase in reported risk behaviours in this population in North America, ${ }^{2}$ Sydney, ${ }^{3}$ Paris, ${ }^{4}$ and Berlin. ${ }^{5}$ This trend has also been described in London, ${ }^{67}$ with one study reporting that the prevalence of unprotected anal intercourse (UAI) with a casual partner of unknown or discordant HIV status more than doubled between 1998 and 2002, from $7 \%$ to $16 \%{ }^{8}$ Increases in HIV infections in homosexual men have been reported in Canada, ${ }^{9}$ the Netherlands, ${ }^{10}$ and the United States. ${ }^{11}$ In England, data suggest an upward trend in HIV transmissions in homosexual men in 2002..2 In Scotland diagnosed infections increased from 546 in 2002 to 604 in $2003 . .^{13} 14$

Since 1996 we have been surveying the sexual and HIV testing behaviour of homosexual men in Scotland, ${ }^{15}{ }^{16}$ as part of the evaluation of the Gay Men's Task Force (GMTF) sexual health intervention. ${ }^{17} 18$ Has homosexual men's sexual risk behaviour for HIV infection increased in Scotland, as elsewhere in the developed world? What is the relation of HIV testing and sexual risk behaviour? What explanations are there for changes in sexual risk behaviour in homosexual men? In this paper we report on three waves of data collection in "gay" bars in Scotland since 1996, in order to answer these questions.

\section{METHODS}

Repeat cross sectional studies of homosexual men took place in Glasgow and Edinburgh in 1996, 1999, and 2002. The methods used are described in detail elsewhere. ${ }^{19}$ Time and location sampling was used to recruit representative samples of men visiting the gay bars in each city (five bars in Glasgow and Edinburgh, respectively, in 1996 and 1999; six in Glasgow and seven in Edinburgh in 2002). Self complete questionnaires were distributed and collected by sessional research staff trained to administer them in bar settings. Men were asked for demographic information, recent (last month and last year) sexual behaviour (number of sexual partners, partner type, last occasion of anal intercourse with and without condoms), and treatment optimism (in 1999 and 2002). This was measured using two single item scales: optimism 1, "I am less worried about HIV infection now that treatments have improved" and optimism 2, "I believe that new drug therapies make people with HIV less infectious." ${ }^{20}$ Men who agreed or strongly agreed with the items were categorised as optimistic and men who disagreed or strongly disagreed were categorised as not optimistic. Men were also asked whether they had been HIV tested, in which year this took place, and knowledge of own and partners' antibody status in the previous year. There were questions on sexual health, including sexually transmitted infections (STIs) in the past year. Questionnaires were anonymous and confidential. Ethical approval for each of the surveys was granted by the University of Glasgow ethics committee for nonclinical research involving human subjects.

The Pearson $\chi^{2}$ test was used for bivariate comparisons unless otherwise stated and multivariate logistic regression was used to produce adjusted odds ratios and to assess their significance. Interactions between survey year and the confounding variables were examined and significant interactions are reported in the results.

\section{RESULTS}

A total of 6508 men have participated in the surveys (response rates in parentheses). In 1996, 2276 men (79\%) were surveyed; 1245 (77\%) in Glasgow and 1031 (80\%) in Edinburgh. In 1999, 2498 men (78\%) were surveyed; 1442 $(75 \%)$ in Glasgow and $1056(80 \%)$ in Edinburgh. In 2002, 1734 men (62\%) were surveyed; 972 (63\%) in Glasgow and $762(61 \%)$ in Edinburgh.

Abbreviations: GMTF, Gay Men's Task Force; HAART, highly active antiretroviral therapy; STI, sexually transmitted infections; UAI, unprotected anal intercourse 
Table 1 1996, 1999, and 2002 survey demographics $(n=6508)$

\begin{tabular}{|c|c|c|c|c|c|c|c|c|}
\hline & \multicolumn{2}{|l|}{1996} & \multicolumn{2}{|l|}{1999} & \multicolumn{2}{|l|}{2002} & \multirow[b]{2}{*}{$\chi^{2}(d f)$} & \multirow[b]{2}{*}{ p Value } \\
\hline & No & $\%$ & No & $\%$ & No & $\%$ & & \\
\hline \multicolumn{9}{|l|}{ Survey location } \\
\hline Glasgow & 1245 & 54.7 & 1442 & 57.7 & 972 & 56.1 & $4.46(2)$ & 0.1 \\
\hline Edinburgh & 1031 & 45.3 & 1056 & 42.3 & 762 & 43.9 & & \\
\hline \multicolumn{9}{|l|}{ Age } \\
\hline $15-25$ years & 620 & 27.6 & 614 & 25.6 & 528 & 32.2 & $21.37(2)$ & $<0.001$ \\
\hline $26+$ years & 1630 & 72.4 & 1788 & 74.4 & 1114 & 67.8 & & \\
\hline \multicolumn{9}{|l|}{ Social class } \\
\hline Manual & 547 & 28.2 & 485 & 23.7 & 335 & 24.5 & $11.83(2)$ & 0.003 \\
\hline Non-manual & 1392 & 71.8 & 1565 & 76.3 & 1031 & 75.5 & & \\
\hline \multicolumn{9}{|l|}{ Qualifications } \\
\hline Secondary & 487 & 24.6 & 470 & 21.6 & 286 & 20.1 & $11.32(4)$ & 0.023 \\
\hline Further & 728 & 36.8 & 819 & 37.6 & 550 & 38.6 & & \\
\hline Higher & 761 & 38.5 & 891 & 40.9 & 588 & 41.3 & & \\
\hline \multicolumn{9}{|l|}{ Area of residence } \\
\hline Glasgow & 896 & 41.5 & 1046 & 43.7 & 650 & 40.4 & $27.56(6)$ & $<0.001$ \\
\hline Edinburgh & 769 & 35.6 & 776 & 32.4 & 589 & 36.6 & & \\
\hline Rest of Scotland & 367 & 17.0 & 362 & 15.1 & 273 & 17.0 & & \\
\hline \multirow{2}{*}{\multicolumn{9}{|c|}{ Frequency of bar use }} \\
\hline & & & & & & & & \\
\hline Once a month or less & 301 & 13.5 & 313 & 13.1 & 316 & 19.5 & $57.0(6)$ & $<0.001$ \\
\hline $2 / 3$ times a month & 682 & 30.5 & 746 & 31.2 & 381 & 23.5 & & \\
\hline $1 / 2$ times a week & 921 & 41.2 & 994 & 41.5 & 660 & 40.7 & & \\
\hline $4 / 5$ times a week & 330 & 14.8 & 340 & 14.2 & 264 & 16.3 & & \\
\hline \multicolumn{9}{|l|}{ HIV optimism 1} \\
\hline Optimistic & \multicolumn{2}{|l|}{ NA } & 235 & 13.9 & 345 & 23.2 & $45.97(1)$ & $<0.001$ \\
\hline \multirow{2}{*}{\multicolumn{9}{|c|}{ HIV optimism 2}} \\
\hline & & & & & & & & \\
\hline Optimistic & \multirow{2}{*}{\multicolumn{2}{|c|}{ NA }} & 129 & 7.6 & 186 & 12.5 & $21.13(1)$ & $<0.001$ \\
\hline Not optimistic & & & 1565 & 92.4 & 1303 & 87.5 & & \\
\hline
\end{tabular}

Demographic differences between the surveys are shown in table 1. In 2002 the sample was significantly younger and reported higher education levels than in the previous surveys. The social class distribution also changed with the proportion in manual social class groups (IIIM, IV, V) decreasing. Frequency of bar use also varied significantly between the surveys. Over $70 \%$ of the samples in each wave were surveyed in their home cities. HIV treatment optimism increased significantly between 1999 and 2002 .

At each wave almost all men reported homosexual contact in the previous year $(97 \%$ in every year) and over three quarters reported anal intercourse. Between 1996 and 1999 there was no significant change in behaviour, but in the 2002 survey, anal intercourse and UAI increased significantly (table 2). Among men reporting UAI, the proportion reporting this as being with casual partners and the proportion reporting this as being with more than one partner also increased significantly. Multivariate logistic regression was used to produce adjusted odds ratios, controlling for age, social class, qualification level, area of residence, frequency of bar use, and HIV optimism because there were significant differences in these factors between

Table 2 Reported sexual risk behaviour in the previous year in 1996, 1999, and $2002(n=6508)$

\begin{tabular}{|c|c|c|c|c|c|c|c|c|}
\hline & \multicolumn{2}{|l|}{1996} & \multicolumn{2}{|l|}{1999} & \multicolumn{2}{|l|}{2002} & \multirow[b]{2}{*}{$\chi^{2}(2 \mathrm{df}) \dagger$} & \multirow[b]{2}{*}{ p Value } \\
\hline & $\overline{\text { Not }}$ & $\% \dagger$ & $\overline{\text { Not }}$ & \%† & Not & $\% \dagger$ & & \\
\hline \multicolumn{9}{|l|}{ Homosexual contact } \\
\hline Yes & 2163 & 97.4 & 2296 & 96.8 & 1635 & 96.7 & 2.45 & 0.3 \\
\hline No & 57 & 2.6 & 77 & 3.2 & 56 & & & \\
\hline Adjusted odds ratio $(95 \% \mathrm{Cl})$ & 1 & & 0.77 & (0.49 to 1.22$)$ & 0.84 & $(0.49-1.45)$ & & \\
\hline \multicolumn{9}{|l|}{ Anal intercourse } \\
\hline Yes & 1660 & 74.7 & 1830 & 76.7 & 1349 & 80.4 & 18.10 & $<0.001$ \\
\hline No & 563 & 25.3 & 555 & 23.3 & 328 & 19.6 & & \\
\hline Adjusted odds ratio $(95 \% \mathrm{Cl})$ & 1 & & 1.09 & (0.91 to 1.32$)$ & 1.35 & $(1.07$ to 1.70$)$ & & 0.011 \\
\hline \multicolumn{9}{|l|}{ Unprotected anal intercourse } \\
\hline Yes & 711 & 32.2 & 782 & 33.5 & 708 & 43.0 & 54.47 & $<0.001$ \\
\hline No & 1496 & 67.8 & 1552 & 66.5 & 940 & 57.0 & & \\
\hline Adjusted odds ratio $(95 \% \mathrm{Cl})$ & 1 & & 1.12 & (0.94 to 1.33 ) & 1.61 & $(1.31$ to 1.96$)$ & & $<0.001$ \\
\hline \multicolumn{9}{|l|}{ Unprotected anal intercourse, partner type* } \\
\hline Regular & 396 & 62.2 & 492 & 63.7 & 373 & 54.0 & 16.16 & $<0.001$ \\
\hline Casual & 241 & 37.8 & 280 & 36.3 & 318 & 46.0 & & \\
\hline Adjusted odds ratio (95\% Cl) & 1 & & 1.10 & (0.82 to 1.46$)$ & 1.65 & $(1.18$ to 2.30$)$ & & 0.003 \\
\hline \multicolumn{9}{|l|}{$\begin{array}{l}\text { Unprotected anal intercourse, number of } \\
\text { partners* }\end{array}$} \\
\hline One & 528 & 74.3 & 571 & 73.0 & 474 & 66.9 & 10.73 & 0.005 \\
\hline More than one & 183 & 25.7 & 211 & 27.0 & 234 & 33.1 & & \\
\hline Adjusted odds ratio $(95 \% \mathrm{Cl})$ & 1 & & 1.25 & $(0.92$ to 1.69$)$ & 1.59 & (1.12 to 2.25$)$ & & 0.009 \\
\hline
\end{tabular}


Table 3 Unadjusted and multivariate logistic regressions for UAI with casual partners and UAI with more than one partner

\begin{tabular}{|c|c|c|c|c|c|c|}
\hline & \multicolumn{3}{|c|}{ Casual partners $(n=6460)$} & \multicolumn{3}{|c|}{ More than one partner $(n=6448)$} \\
\hline & $\overline{O R}$ & $95 \% \mathrm{Cl}$ & p Value & $\mathrm{OR}$ & $95 \% \mathrm{Cl}$ & $\mathrm{p}$ Value \\
\hline \multicolumn{7}{|l|}{ Unadjusted } \\
\hline \multicolumn{7}{|l|}{ Survey } \\
\hline 1996 & 1 & & & 1 & & \\
\hline 1999 & 1.06 & 0.88 to 1.27 & 0.5 & 1.05 & 0.86 to 1.30 & 0.6 \\
\hline 2002 & 1.91 & 1.60 to 2.29 & $<0.001$ & 1.80 & 1.47 to 2.21 & $<0.001$ \\
\hline \multicolumn{7}{|l|}{ Multivariate } \\
\hline \multirow{2}{*}{\multicolumn{7}{|c|}{ Survey }} \\
\hline 1996 & 1 & & & & & \\
\hline 1999 & 1.25 & 0.99 to 1.58 & 0.066 & 1.24 & 0.95 to 1.61 & 0.1 \\
\hline 2002 & 2.23 & 1.71 to 2.92 & $<0.001$ & 2.03 & 1.50 to 2.75 & $<0.001$ \\
\hline Aged $26+$ years & 0.82 & 0.69 to 0.97 & 0.02 & 0.70 & 0.58 to 0.84 & $<0.001$ \\
\hline Manual social class & 1.16 & 0.96 to 1.40 & 0.1 & 1.10 & 0.89 to 1.37 & 0.5 \\
\hline \multicolumn{7}{|l|}{ Qualifications } \\
\hline Secondary & 1 & & & 1 & & \\
\hline Further & 0.90 & 0.73 to 1.12 & 0.3 & 0.94 & 0.74 to 1.20 & 0.6 \\
\hline Higher & 0.81 & 0.65 to 1.01 & 0.07 & 0.94 & 0.73 to 1.21 & 0.6 \\
\hline \multicolumn{7}{|l|}{ Area of residence } \\
\hline Glasgow & 1 & & & 1 & & \\
\hline Edinburgh & 1.05 & 0.88 to 1.24 & 0.6 & 1.06 & 0.87 to 1.28 & 0.6 \\
\hline Rest of Scotland & 0.89 & 0.70 to 1.11 & 0.3 & 0.92 & 0.71 to 1.19 & 0.5 \\
\hline Rest of UK & 0.94 & 0.68 to 1.29 & 0.7 & 0.91 & 0.62 to 1.32 & 0.6 \\
\hline \multicolumn{7}{|l|}{ Frequency of bar use } \\
\hline Once a month or less & 1 & & & 1 & & \\
\hline $2 / 3$ times a month & 1.36 & 1.04 to 1.78 & 0.025 & 1.52 & 1.09 to 2.12 & 0.014 \\
\hline $1 / 2$ times a week & 1.57 & 1.22 to 2.02 & $<0.001$ & 1.95 & 1.43 to 2.67 & $<0.001$ \\
\hline $4 / 5$ times a week & 2.26 & 1.70 to 2.99 & $<0.001$ & 3.13 & 2.23 to 4.37 & $<0.001$ \\
\hline HIV optimism 1 & 1.38 & 1.05 to 1.83 & 0.02 & 1.74 & 1.28 to 2.37 & $<0.001$ \\
\hline HIV optimism 2 & 1.30 & 0.92 to 1.84 & 0.1 & 1.03 & 0.69 to 1.53 & 0.9 \\
\hline
\end{tabular}

the surveys (table 1). Survey location was not significant so was not included in the multivariate model. The increases in 2002 remained significant after controlling for the demographic variables.

Men reporting UAI with casual or multiple partners are at risk of HIV and other STIs and these men were compared with the rest of the sample. In 1996, 10.7\% (241/2259 men) and, in $1999,11.2 \%$ (280/2491 men) reported UAI with casual partners, compared with $18.6 \%$ in 2002 (318/1710 men) ( $p<0.001)$. In 1996, 8.1\% (183/2258 men) and, in 1999, 8.5\% (211/2482 men) reported UAI with more than one partner, compared with $13.7 \%$ in 2002 (234/1708 men) $(\mathrm{p}<0.001)$. Logistic regression was used to assess the change in UAI with casual partners and with multiple partners between the surveys. Using 1996 as the baseline, the unadjusted odds of UAI with casual partners and of UAI with more than one partner increased significantly in 2002, but not in 1999 (table 3).

After adjusting for the demographic variables, the increase in UAI with casual partners in 2002 remained significant (table 3). In the multivariate model, the likelihood of UAI with casual partners was also significantly higher for men who made more frequent visits to bars and for men who agreed with optimism l ("I am less worried about HIV infection now that treatments have improved"), and lower for older men. There were no significant interactions between these variables and survey year, demonstrating the independent effects of each and that the influence of age, bar use, and optimism had not changed over time. There was a significant interaction between 2002 survey year and manual social class ( $\mathrm{OR}=0.62,95 \% \mathrm{CI} 0.40$ to 0.96 ), demonstrating that, while UAI with casual partners was more likely among men in manual jobs, the rate of increase was greater for men in non-manual employment.

The increase in UAI with more than one partner in 2002 also remained significant after adjusting for the demographic variables. The likelihood of UAI with more than one partner was also significantly higher for men who made more frequent visits to bars and for men who agreed with optimism l ("I am less worried about HIV infection now that treatments have improved"), and lower for older men. There was no significant interaction between age, HIV optimism, and survey year, demonstrating the independent effects of each. There was a significant interaction between 2002 survey year and men reporting visiting bars once or twice a week (OR $=2.47,95 \%$ CI 1.17 to 5.23$)$, demonstrating that the rate of increase in UAI with more than one partner had been greater for these men.

Men reporting UAI with casual partners were asked if they knew their partners' HIV status. Again using 1996 as baseline, there was a significant increase in men reporting that they always knew casual partners' status, after adjusting for demographic factors (table 4). The adjusted odds of reporting that casual partners were either possibly or definitely HIV positive decreased significantly. However, HIV testing did not increase among men who reported UAI with casual partners.

The multivariate analyses were run separately for men who had had an HIV test and men who had never been tested (table 5). Never tested men who engaged in UAI may have had partners of discordant antibody status, as they were unaware of their own HIV status. Even among tested men, only $19 \%$ reported that they "always" knew their casual partners' status, demonstrating that the majority of tested men $(81 \%)$ also engaged in non-concordant UAI. With 1996 as the baseline, the adjusted odds of UAI with casual partners increased significantly in 2002 for tested men and for never tested men. The adjusted odds of UAI with more than one partner increased significantly for never tested men but not for tested men. However, with 1999 as the baseline, the increase in 2002 was significant for tested men (OR $=1.54,95 \%$ CI 1.16 to 2.04$)$. The adjusted odds of UAI with casual partners and of UAI with more than one partner also increased significantly in 1999 for never tested men. Of the never tested men, those who were older and those with higher education had lower odds of 
Table 4 Knowledge of own and partners' HIV status among men reporting UAl with casual partners $(n=839)$

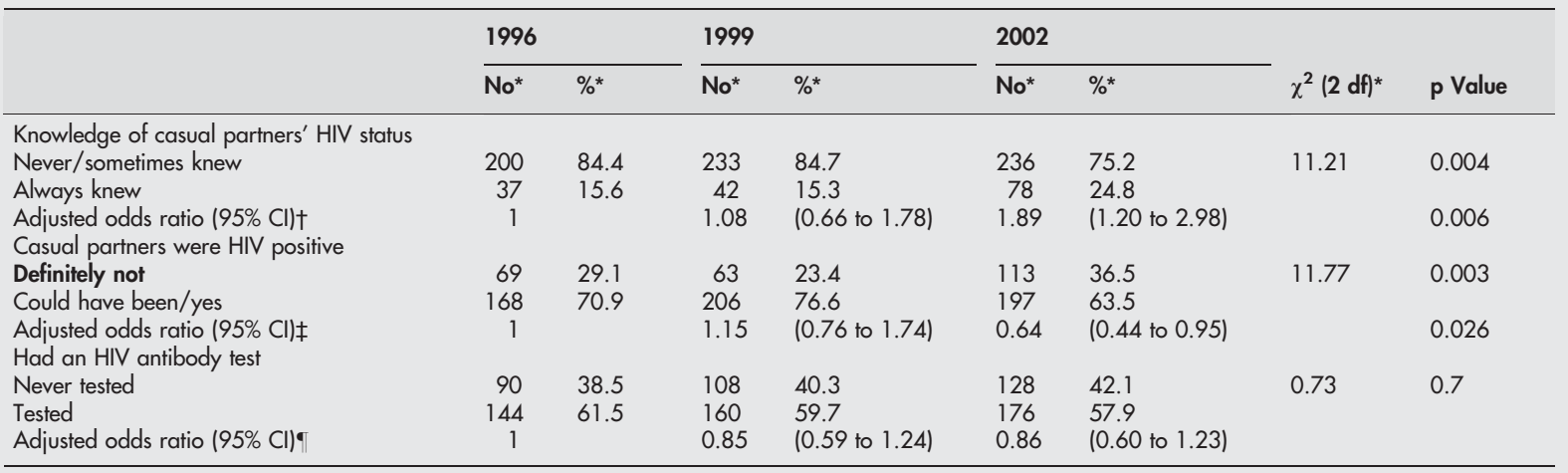

*Multivariate logistic regression adjusted for age, social class, qualification level, area of residence, and frequency of bar use.

†Age 26 years or older $(\mathrm{OR}=0.49,95 \% \mathrm{Cl} 0.33$ to 0.72 ).

†Age 26 years or older $(\mathrm{OR}=1.94,95 \% \mathrm{Cl} 1.38$ to 2.73$)$.

-Age 26 years or older $(\mathrm{OR}=1.67,95 \% \mathrm{Cl} 1.21$ to 2.30$)$ and living elsewhere in Scotland than Glasgow or Edinburgh (OR=0.63, $95 \% \mathrm{Cl} 0.41$ to 0.99$)$.

reporting UAI with casual partners, compared to younger men and those with secondary education only. Among tested and never tested men, the adjusted odds of UAI with more than one partner were also significantly lower for older men than younger men. Frequency of bar use remained significant in all of the models. HIV optimism 1 remained significant in the models for UAI with more than one partner but not in the models for UAI with casual partners. However, for never tested men there was a significant interaction between survey year and optimism l $(\mathrm{OR}=0.43,95 \%$ CI 0.20 to 0.94$)$, demonstrating that the rate of increase in UAI with casual partners was greater among those who were not optimistic than among those who were.

The commercial gay scene in Glasgow and Edinburgh changed between the three surveys with some of the original bars closing and being replaced by others; but limiting the analysis to the five bars that were surveyed in every year of data collection (two in Glasgow and three in Edinburgh) did not change the results.

\section{DISCUSSION}

The sexual risk behaviour of homosexual men in Scotland increased between 1996 and 2002, as it has done elsewhere in Europe, and in North America and Australia. ${ }^{21}$ The increase in UAI with one or more and casual partners that we found in 2002 occurred regardless of whether men had been tested for HIV or not. There are limitations to these data. Firstly, this does not constitute a trend in Scotland as we have evidence of an increase only in the 2002 survey; future surveys will determine the extent to which this is truly a trend, or simply variability in behaviour over time. Secondly, we are concerned that there has been a decline in the number of men surveyed and, as with recent survey in London, a fall in the response rate. ${ }^{7}$ However, we think the data on increased sexual risk behaviours are robust, and it is necessary now to ask what accounts for this increase, and the apparent increase in confidence that men knew the HIV status of the casual partners with whom they had UAI?

With regard to increased risk behaviour, the explanation employed by many researchers is of greater "treatment

Table 5 Multivariate logistic regressions for UAI with casual partners and UAI with more than one partner for HIV tested and never tested men

\begin{tabular}{|c|c|c|c|c|c|c|c|c|c|c|c|c|}
\hline & \multicolumn{6}{|c|}{ Casual partners } & \multicolumn{6}{|c|}{ More than one partner } \\
\hline & \multicolumn{3}{|c|}{ Tested men $(n=3196)$} & \multicolumn{3}{|c|}{ Never tested men $(n=3034)$} & \multicolumn{3}{|c|}{ Tested men ( $n=3192$ ) } & \multicolumn{3}{|c|}{ Never tested men $(n=3030)$} \\
\hline & $\overline{O R}$ & $95 \% \mathrm{Cl}$ & p Value & OR & $95 \% \mathrm{Cl}$ & p Value & OR & $95 \% \mathrm{Cl}$ & p Value & OR & $95 \% \mathrm{Cl}$ & p Value \\
\hline \multicolumn{13}{|l|}{ Survey } \\
\hline 1996 & 1 & & & 1 & & & 1 & & & 1 & & \\
\hline 1999 & 1.09 & 0.78 to 1.53 & 0.6 & 1.56 & 1.10 to 2.22 & 0.012 & 0.92 & 0.63 to 1.35 & 0.7 & 2.21 & 1.47 to 3.33 & $<0.001$ \\
\hline 2002 & 1.75 & 1.20 to 2.55 & 0.004 & 3.26 & 2.16 to 4.92 & $<0.001$ & 1.41 & 0.92 to 2.17 & 0.1 & 3.56 & 2.20 to 5.75 & $<0.001$ \\
\hline Aged $26+$ years & 0.84 & 0.66 to 1.06 & 0.1 & 0.73 & 0.56 to 0.95 & 0.017 & 0.63 & 0.49 to 0.81 & $<0.001$ & 0.73 & 0.54 to 0.98 & 0.039 \\
\hline Manual social class & 1.15 & 0.90 to 1.48 & 0.3 & 1.12 & 0.83 to 1.52 & 0.5 & 0.91 & 0.68 to 1.22 & 0.5 & 1.31 & 0.93 to 1.83 & 0.1 \\
\hline \multicolumn{13}{|l|}{ Qualifications } \\
\hline Secondary & 1 & & & 1 & & & 1 & & & 1 & & \\
\hline Further & 0.99 & 0.74 to 1.32 & 1.0 & 0.81 & 0.58 to 1.12 & 0.2 & 1.11 & 0.80 to 1.55 & 0.5 & 0.82 & 0.56 to 1.20 & 0.3 \\
\hline Higher & 0.86 & 0.64 to 1.16 & 0.3 & 0.65 & 0.45 to 0.92 & 0.016 & 1.06 & 0.76 to 1.48 & 0.8 & 0.73 & 0.49 to 1.10 & 0.1 \\
\hline \multicolumn{13}{|l|}{ Area of residence } \\
\hline Glasgow & 1 & & & 1 & & & 1 & & & 1 & & \\
\hline Edinburgh & 1.01 & 0.80 to 1.27 & 0.9 & 1.12 & 0.84 to 1.48 & 0.4 & 1.11 & 0.86 to 1.43 & 0.4 & 0.93 & 0.67 to 1.29 & 0.7 \\
\hline Rest of Scotland & 0.85 & 0.61 to 1.19 & 0.3 & 1.10 & 0.79 to 1.52 & 0.6 & 0.89 & 0.61 to 1.31 & 0.6 & 1.03 & 0.71 to 1.51 & 0.9 \\
\hline Rest of UK & 0.96 & 0.65 to 1.44 & 0.9 & 0.83 & 0.46 to 1.49 & 0.5 & 0.81 & 0.50 to 1.32 & 0.4 & 0.82 & 0.42 to 1.58 & 0.5 \\
\hline \multicolumn{13}{|l|}{ Frequency of bar use } \\
\hline Once a month or less & 1 & & & 1 & & & 1 & & & 1 & & \\
\hline $2 / 3$ times a month & 1.59 & 1.11 to 2.28 & 0.012 & 1.06 & 0.70 to 1.59 & 0.8 & 1.40 & 0.92 to 2.13 & 0.1 & 1.63 & 0.94 to 2.85 & 0.08 \\
\hline $1 / 2$ times a week & 1.85 & 1.31 to 2.61 & $<0.001$ & 1.24 & 0.85 to 1.82 & 0.3 & 1.76 & 1.18 to 2.61 & 0.005 & 2.21 & 1.32 to 3.72 & 0.003 \\
\hline $4 / 5$ times a week & 2.27 & 1.55 to 3.31 & $<0.001$ & 2.20 & 1.44 to 3.38 & $<0.001$ & 2.49 & 1.62 to 3.81 & $<0.001$ & 4.09 & 2.35 to 7.14 & $<0.001$ \\
\hline HIV optimism 1 & 1.38 & 0.96 to 1.99 & 0.08 & 1.38 & 0.88 to 2.17 & 0.2 & 1.87 & 1.26 to 2.78 & 0.002 & 1.71 & 1.04 to 2.81 & 0.03 \\
\hline HIV optimism 2 & 1.33 & 0.83 to 2.13 & 0.2 & 1.39 & 0.82 to 2.36 & 0.3 & 0.94 & 0.55 to 1.63 & 0.8 & 1.13 & 0.62 to 2.06 & 0.7 \\
\hline
\end{tabular}


optimism" among homosexual men after 1996 and the availability of combination therapies. There are many scales, with variable items, that measure treatment optimism, but we adopted the two dimensions that have been identified as being core to the concept. ${ }^{20}$ The first relates to reduced concern about the threat of HIV infection because of the dramatic impact that highly active antiretroviral therapy (HAART) has had on morbidity and mortality. The second is a belief that HAART has resulted in less risk of transmission between HIV positive people on treatment and their uninfected partners.

"Treament optimism" appeared to be associated with increased risk behaviour in homosexual men, particularly in Australia $^{3}$ and the United States. ${ }^{22}{ }^{23}$ However, we found that while treatment optimism increased over the 3 years in which we included survey questions on this topic (1999, 2002) and that it was significantly associated with risk behaviour, multivariate analysis demonstrated that optimism alone did not account for the increase in risk. Indeed, among our never tested men, the rate of increase in UAI with casual partners was actually higher among those who were not optimistic. This is reported in more detail elsewhere. ${ }^{24}$ In London, researchers also found increased risk behaviour regardless of whether or not men were optimistic on either key dimension of the scale; the rate of increase in risk behaviour was similar among HIV positive, negative, and never tested men over time. ${ }^{8}$

Internationally, it has been found that the majority of homosexual men are realistic, rather than optimistic, in their assessment of the impact of treatments, but a minority do report such optimism, and risk behaviour among them is higher. ${ }^{20}$ Arguably, we should now move beyond "treatment optimism" to recognise that there has been a massive cultural shift in the perception of HIV in recent years: rather than being inevitably life threatening, HIV is now seen as a chronic disease requiring life long management. Thus, treatment optimism itself does not explain increased risk behaviour among men in our surveys, but there may have been a shift in perceptions of HIV associated with new treatments. This requires further and more focused research.

What of our finding of an increase in confidence that men knew the HIV status of the casual partners with whom they had UAI, despite there being no increase in the uptake of HIV testing over the period 1996-2002? Although we have not collected data in this study on willingness to disclose HIV status, it is not evident in UK studies of HIV positive men. ${ }^{25-27}$ Recent data also show that, in a community based survey in London, a third of HIV positive men were unaware of their antibody status. ${ }^{7}$ Among homosexual men in Glasgow and Edinburgh, there may be increased confidence in, and an assumption of, seroconcordance with casual sexual partners. In Scotland HIV prevalence remained low over the period 1996-2002. ${ }^{13}$ In this situation, Scottish homosexual men may think that if they are HIV negative (or never tested but assumed to be negative) most if not all of their partners will also be negative.

There was no change in risk behaviours between 1996 and 1999. In the middle of this period (June 1997 to October 1998) the GMTF, a peer led sexual health promotion intervention, was active in Glasgow ${ }^{17}{ }^{18}$ and there were other health promotion activities targeted to homosexual men in Edinburgh. The biggest increase in risk behaviour occurred between 1999 and 2002. Our observation is that health promotion activities in the bars in both cities were less evident and less focused upon HIV during this period. Alongside this, national awareness raising campaigns targeted at homosexual men were limited to dimensions of social exclusion, such as stigma, and were considerably reduced in comparison with previous years (Roy Kilpatrick,
Key messages

- This is the first report of increasing sexual risk behaviour for HIV infection among homosexual men in Scotland

- Over the period 1996-2002 reported unprotected anal intercourse with casual partners nearly doubled (from $10.7 \%$ to $18.6 \%$ )

- More men reported that they knew the HIV antibody status of their casual partners, but this was not associated with an increase in HIV testing

- The increase in sexual risk behaviour took place at a time when there were few targeted prevention programmes for HIV in Scotland

\section{Policy implications}

- HIV prevention messages targeted to homosexual men should be a priority for the newly developed sexual health strategies for England and Wales and Scotland. Increased availability of HIV testing for homosexual men is also warranted.

HIV Scotland, personal communication). Further research is required to determine whether these observations are supported by data on expenditure on HIV prevention in Scotland during this period, and activity analysis of health promotion agencies in bars and elsewhere to determine whether the following hypothesis is supported: that in this situation, and with no reported increases in HIV incidence among homosexual men in Scotland, the threat of HIV has diminished.

The term "prevention fatigue" has been applied to individuals and populations: a situation in which the message about safer sex has been repeated so often that people ignore or actively refuse to hear it. The same may apply to governments and health agencies, but is more appropriately termed "prevention failure" as the safer sex message has simply not been communicated with any vigour for such a long period of time.

We are suggesting that there is a direct link between increased (but undue) confidence on the part of homosexual men that they share the (negative) serostatus of their casual partners, and the apparent failure to deliver prevention messages by health promotion agencies. The newly developed sexual health strategies for England and Wales ${ }^{28}$ and Scotland ${ }^{29}$ have the opportunity to correct this situation. We will be undertaking further surveys to monitor their progress, and to inform contemporary prevention activity.

\section{ACKNOWLEDGEMENTS}

This research was supported by the UK Medical Research Council. We thank Jonathan Elford for comments on an earlier version of the paper; Paul Flowers, Jamie Frankis, Claire Marriott, and Christopher Thow for their contributions to data collection in 1996 and/or 1999; the survey staff who carried out the interviews at each wave of data collection; bar staff and managers in Glasgow and Edinburgh. Our greatest thanks are to the men who agreed to participate in the studies in 1996, 1999, and 2002.

\section{CONTRIBUTORS}

GH designed the study and contributed to data collection in 1996, 1999, and 2002; he wrote and revised subsequent drafts of the manuscript; LW organised and contributed to data collection in 2002, 
undertook data analysis on each wave of the study, wrote, and contributed to each draft of the manuscript.

\section{Authors' affiliations}

G J Hart, L M Williamson, MRC Social and Public Health Sciences Unit, University of Glasgow, 4 Lilybank Gardens, Glasgow G12 8RZ, UK

Competing interests: None declared.

\section{REFERENCES}

1 King E. Safety in numbers. London: Cassell, 1993.

2 Wolitski R, Valdiserri R, Denning P, et al. Are we headed for a resurgence of the HIV epidemic among men who have sex with men? Am J Public Health 2001;91:883-8.

3 Van de Ven P, Prestage G, Crawford J, et al. Sexual risk behaviour increases and is associated with HIV optimism among HIV-negative and HIV-positive gay men in Sydney over the 4 year period to February 2000. AIDS 2000; 14:2951-3.

4 Adam P, Hauet E, Caron C. Recrudescence des prises de risque et des MST parmi les gays. Resultats de l'enquete press gay 2000. Paris: L'Institut de Veille Sanitaire, 2001

5 Bochow M. Schwule M. AIDS und safer sex: Neue Entwicklungen. Berlin: Deutsche AIDS-Hilfe eV, 2001.

6 Dodds JP, Nardone A, Mercey DE, et al. Increase in high risk sexual behaviour among homosexual men, London 1996-8: cross sectional, questionnaires study. BMJ 2000;320:1510-1.

7 Dodds JP, Mercey DE, Parry JV, et al. Increasing sexual risk behaviour and high levels of undiagnosed HIV infection in a community sample of homosexual men. Sex Transm Infect 2004;80:236-40.

8 Elford J, Bolding G, Sherr L. High risk sexual behaviour increases among London gay men between 1998-2001: what is the role of HIV optimism? AIDS 2002; 16:1537-44.

9 Calzavara L, Burchell A, Major C, et al. Increases in HIV incidence among men who have sex with men undergoing repeat diagnostic HIV testing in Ontario, Canada. AIDS 2002;16:1655-61.

10 Dukers N, Spaargaren J, Geskus R, et al. HIV incidence on the increase among homosexual men attending an Amsterdam sexually transmitted disease clinic: using a novel approach for detecting recent infections. AIDS 2002; 16:F19-24.

11 Katz M, Schwarcz S, Kellogg T, et al. Impact of highly active antiretroviral treatment on HIV seroincidence among men who have sex with men: San Francisco. Am J Public Health 2002;92:388-94.
12 Murphy G, Charlett A, Brown A, et al. Is HIV incidence increasing in homo/ bisexual men attending GUM clinics in England, Wales and Northern Ireland? Commun Dis Public Health 2004;7:11-14.

13 Health Protection Agency. Renewing the focus: HIV and other sexually transmitted infections in the United Kingdom in 2002. London: Health Protection Agency, 2003.

14 UK Collaborative Group for HIV Surveillance. Focus on prevention: HIV and other sexually transmitted infections in the United Kingdom in 2003. London: Health Protection Agency, 2004.

15 Hart GJ, Flowers P, Der GJ, et al. Homosexual men's HIV-related sexual risk behaviour in Scotland. Sex Transm Infect 1999;75:242-6.

16 Hart G, Williamson L, Flowers P, et al. Gay men's HIV testing behaviour in Scotland. AIDS Care 2002; 14:665-74.

17 Flowers P, Hart GJ, Williamson LM, et al. Does bar-based, peer-led sexual health promotion have a community-level effect among gay men in Scotland? Int J STDs AIDS 2002;13:102-8.

18 Williamson LM, Hart GJ, Flowers P, et al. The Gay Men's Task Force: the impact of peer education on the sexual health behaviour of homosexual men in Glasgow. Sex Transm Infect 2001;77:427-32.

19 Flowers P, Frankis J, Hart G. Evidence and the evaluation of a communitylevel intervention: researching the Gay Men's Task Force. In: Watson J, Platt S, eds. Researching health promotion. London: Routledge, 2000:102-24.

20 International Collaboration on HIV Optimism. HIV treatments optimism among gay men: an international perspective. J AIDS 2003:32:545-50.

21 Elford J, Hart G. If HIV prevention works, why are rates of high risk sexual behaviour increasing among men who have sex with men? AIDS Educ Prev 2003; 15:294-308.

22 Kelly J, Hoffman R, Rompa D, et al. Protease inhibitor combination therapies and perceptions of gay men regarding AIDS severity and the need to maintain safer sex. AIDS 1998:F91-F5.

23 Vanable $\mathrm{P}$, Ostrow D, McKirnan D, et al. Impact of combination therapies on HIV risk perceptions and sexual risk among HIV-positive and HIV-negative gay and bisexual men. Health Psychol 2000;19:134-45.

24 Williamson L, Hart G. HIV optimism does not explain increases in sexual risk behaviour among gay men in Scotland. AIDS 2004; 18:834-5.

25 Keogh P, Weatherburn P, Stephens M. Relative safety: risk and unprotected anal intercourse among gay men diagnosed with HIV. London: Sigma Research, University of Portsmouth, 1999.

26 Green G, Sobo E. The endangered self: managing the social risks of HIV London: Routledge, 2000.

27 Hart G, Davis M, Imrie J, et al. "If I'm not asked directly then I don't always tell people": disclosure of HIV status to sexual partners by gay men on HAART. International Congress of Sexually Transmitted Infections. Berlin, 2001.

28 Department of Health. The National Strategy for Sexual Health: better prevention, better services, better sexual health. London: DoH, 2001.

29 Scottish Executive. Enhancing sexual wellbeing in Scotland: a sexual health and relationships strategy. Edinburgh: Scottish Executive, 2003. 